\title{
The Score Difference of Emotional Intelligence among Engineering Students at Different Levels of Academic Year
}

\author{
Nizaroyani Saibani ${ }^{1}$, Idham Sabtu ${ }^{1}$, Norhamidi Muhamad ${ }^{1}$, Dzuraidah Abd. Wahab ${ }^{1} \&$ Ja' afar Sahari $^{1}$ \\ ${ }^{1}$ Department of Mechanical and Material Engineering, Faculty of Engineering and Built Environment, Universiti \\ Kebangsaan Malaysia, Selangor, Malaysia \\ Correspondence: Nizaroyani Saibani, Department of Mechanical and Material Engineering, Faculty of \\ Engineering and Built Environment, Universiti Kebangsaan Malaysia, 43600 UKM Bangi, Selangor, Malaysia. \\ Tel: 60-389-216-523. E-mail: nizaroyani@gmail.com
}

\author{
Received: February 7, 2013 Accepted: April 7, 2013 Online Published: April 25, 2013 \\ doi:10.5539/ies.v6n6p72 \\ URL: http://dx.doi.org/10.5539/ies.v6n6p72
}

\begin{abstract}
The number of students from the under-graduate level who have successfully completed their studies is on the increase every year. In the selection process for the best employee-candidate, employers have to take into consideration several factors other than academic excellence, including values that depict EQ or emotional intelligence. This study focuses on looking at the EQ achievement among the under-graduate students at the Faculty of Engineering and Built Environment, Universiti Kebangsaan Malaysia. The EQ scores were measured using the MEQI Test (Malaysian EQ Inventory). The study began by monitoring EQ achievements of a group of students at three consecutive years: Year 1, Year 2 and Year 3 in the faculty. The study is expanded by measuring the EQ of all faculty students at the stage of Year 1, Year 2, Year 3, Year 4, also right after they had completed their studies of four years. Results have shown that, from the three-year data from 2010 to 2012, the overall EQ scores have recorded a marked increase.
\end{abstract}

Keywords: emotional intelligence, undergraduate students, the Malaysian EQ Inventory test

\section{Introduction}

It is part and parcel of skill measurement, that we settle at employing the IQ test or Intelligent Quotient to assess one's wisdom and intelligence. IQ or Intelligent Quotient refers to the division outcome of the intelligence used to assess individual intelligence. The level of intelligence must differ from one another. Normally, one that has high level of IQ is said to have a high level of intelligence. The intelligence, in this context, is always referred to one's mastery in the academic field. Notwithstanding, studies have shared an interesting proof that high level of IQ does not determine one's success in life. A common portrayal found in the news is that an individual who is well-known, has high level of IQ and demonstrates an extraordinary intelligence in his or her academic achievements while they are still young, gradually suffers from the hardship of living life in a normal manner as he or she grows older. Several cases have proven that these individuals fail to build a successful career, undergoing unhealthy social lives and there are even those who make an extreme decision to commit suicide due to their incapability of managing stress and pressure in life. There are also highly educated criminals who have been reported to have committed cyber-crime involving acts of abusing money transactions and hacking websites merely for self-satisfaction. In fact, there are also common reports made by the media, over poor treatment of older citizens by their own children who have good job positions and high career advancements of whom would normally be expected to have high level of IQ.

Emotional intelligence or more commonly known as EQ, is the ability in handling conflicts or the capability in resolving problems. Individuals who have high EQ level should be able to walk and think calmly although tested with various problems. In fact, EQ is able to contribute by way of enhancing one's IQ. Individuals who are able to control their anger, empathy, independence, adaptability to new environment, courtesy also respect for others are individuals who have good EQ development. The good values are essential in preparing one to be happy and succeed in their career later. Therefore, emotional intelligence or EQ needs to be developed and nurtured to create high quality and competitive graduates.

Several studies have been administered in the development of EQ models and the conceptual framework. Salovey and Mayer (1990) have started to use the term "emotional intelligence" and conclude that it has three 
categories in the adaptive capability: emotional assessment and statement, emotional regulations, and the use of emotions in problem-solving. Emotional statement and assessment is divided into verbal and non-verbal components classified into non-verbal assumption and empathy with others. Emotional regulations contain emotional regulations and self-emotion control. The use of emotions in resolving problems include flexible planning, creative thinking, and attention diversion and motivation. This third category is associable with the assessment of student course. The EQ model by Salovey and Mayer (1990), concentrates not only on the emotion but also detectable through the use of emotion.

There are also specific capability models that focus on solution, whereby emotions help in the thinking process. As an example, emotions can prioritise the mind (Mandler, 1975) or allows one to improve skills when making a decision (Lyubomirsky et al., 2005). The concept used in the model development supports the idea whereby EQ can assist in forming an individual to become a successful leader or manager, and become likeable in a given work environment. Therefore, by concentrating on the higher learning students's EQ level, it can help enhance students' marketability after the graduation.

EQ can be used as part of the benchmark in preparing the students to achieve the characteristics of a happy life and also succeed in the new dimension of life, after the higher education period of years. Other EQ models have stressed on a different combination of happiness factors- tolerance towards stress, also self-assumption (Bar-On, 1997), self-adaptation, self-urge (low), and socialization efficacy (Boyatzis \& Sala, 2004; Petrides \& Furnham, 2001); also creative thinking, flexibility, and instinct versus causal determination (Tett. et al., 2005). In fulfilling and achieving high academic requirements it is easy for students to feel such a great pressure. Therefore, they need to be equipped with the skills in managing and controlling stress. EQ is also often regarded as an important criterion in achieving academic and social accomplishments after one has fulfilled the personality and intelligence measurement requirements (Van der Zee et. al., 2002). Janovics and Christiansen (2001) report on a positive outcome in work performance using EQ trait capability steps in their studies. A number of EQ tests have been administered based on previous researches. As an example, Schmidt-Atzert and Buhner (2002) have run the "Test of Emotional Intelligence," embodying the interpretation and assessment of emotional capability, also the capability to understand emotions correctly. Prakash et al. (2007) suggest that EQ is not supposed to be compared with IQ, but rather, it acts as an extension to the individual potential to succeed in a human-oriented environment. Traditional cognitive intelligence or IQ is combined with the non-cognitive intelligence or EQ to help leaders, especially those involved in the educational field, to perform their duties more efficaciously and also able to inspire other individuals to gain success and happiness in their lives.

The need to resolve any inconsistency in results of past work and/or extend the reach of a theoretical formulation. For applied research, this might involve the need to solve a social problem or treat a psychological disorder. When research is driven by the desire to resolve controversial issues, all sides in the debate should be represented in balanced measure in the introduction. Avoid animosity and ad hominem arguments in presenting the controversy. Conclude the statement of the problem in the introduction with a brief but formal statement of the purpose of the research that summarizes the material preceding it. For literature reviews as well as theoretical and methodological articles, also clearly state the reasons that the reported content is important and how the article fits into the cumulative understanding of the field. (Beck, 2001)

\section{Study Objective}

Using the MEQI test, this study presents the development of EQ level for a group of students who had started to enroll in 2010 and are now at their 3rd year (2012). For this group, this study has collected and monitored the data from MEQI since they registered in 2010 at the Faculty of Engineering and Built Environment, UKM. This study presents the EQ level for all students at the Faculty in the academic year 2012/2013 involving First Year, Second Year, Third Year and Fourth Year students from five departments. They have sat for MEQI when they first registered at the early academic year of 2012/2013 in the middle of September until the middle of October 2012. Data were also taken for students who had completed their studies after four years studying at the university and would attend the graduation ceremony in October 2012. They have undertaken the MEQI test in the same time as the other students. 


\section{Method}

Table 1. Sub-domains for MEQI model

\begin{tabular}{|c|c|c|c|c|c|}
\hline & Domain & Sub-domain & & Domain & Sub-domain \\
\hline 1) & $\begin{array}{l}\text { SELF } \\
\text { AWARENESS }\end{array}$ & $\begin{array}{l}\text { emotional awareness, accurate } \\
\text { self assessment, self confidence, } \\
\text { honesty }\end{array}$ & 2) & $\begin{array}{l}\text { SELF } \\
\text { REGULATION }\end{array}$ & $\begin{array}{l}\text { self control, trust worthiness, } \\
\text { responsibility, adaptability, } \\
\text { innovation }\end{array}$ \\
\hline 3) & $\begin{array}{l}\text { SELF } \\
\text { MOTIVATION }\end{array}$ & $\begin{array}{l}\text { Achievement, drive, } \\
\text { commitment, initiative, interest }\end{array}$ & 4) & ЕМРНАТY & $\begin{array}{l}\text { understanding others, } \\
\text { helping others, leveraging } \\
\text { diversity, service orientation, } \\
\text { developing other's potential, } \\
\text { political awareness }\end{array}$ \\
\hline \multirow[t]{2}{*}{ 5) } & $\begin{array}{l}\text { SOCIAL } \\
\text { SKILLS }\end{array}$ & $\begin{array}{l}\text { Influence, conflict management, } \\
\text { leadership, change catalyst, } \\
\text { building bonds, collaboration } \\
\text { and cooperation, team } \\
\text { capabilities, communication }\end{array}$ & 6) & SPIRITUALITY & \\
\hline & & & 7) & MATURITY & \\
\hline
\end{tabular}

This study uses a test labeled as the Malaysian EQ Inventory (MEQI). MEQI is a product from a group of researchers from the UKM (Noriah et al., 2003) whereby this model is constructed using the values and characteristics of Malaysian citizens. Their discovery has validated the existence of five domains suggested by Goleman (1995) which include self awareness, self-regulation, self-motivation, empathy and social skills. Nonetheless, they have indicated that these five domains are insufficient to portray the emotional intelligence of the Malaysians. Therefore, they have suggested that two extra domains should be included into the development of a new model, or MEQI, namely spirituality and maturity to be adapted to the Malaysian traditional culture where the citizens prone to appreciate and respect elder people and practice spiritual aspects in their daily lives.

This study is implemented using MEQI whereby this test is able to assess the EQ level of the engineering students. MEQI also serves as one of the efforts that can identify the domains that need to be acquired by a student, and which domains have low scores. To this end, EQ studies have not been linked yet with students' academic performance and there has been no record concerning students' EQ level. This study is actually still at its infancy, where its main objective lies in the assessment of all EQ domains, starting from the stage where students enroll themselves in their chosen courses until they finish their studies. Every student will sit for the test online, and they will obtain the results based on the scores for all seven domains stated. Every domain stated has their own fragment or what is known as sub-domains enlisted in Table 1 above.

The MEQI test is implemented to see the effectiveness level of the domains involved in EQ also the measure the EQ level of the students of the Faculty. To start the study off, this working paper reports on the level of EQ scores where the results are obtained and divided into two sections. For the first section, data are obtained for the group who had first registered their studies in 2010 and is currently in their third year this year (2012). For these students, this study had gathered the MEQI data since they had registered in 2010 at the Faculty of Engineering and Built Environment, UKM.

The second section presents the EQ level for all students at the Faculty of Engineering and Built Environment, UKM in the academic session of 2012/2013 involving First, Second, Third and Fourth Year students. They have undertaken this MEQI when they started their registration in the beginning of the academic session of 2012/2013 which is in the middle of September until the middle of October 2012. The number of respondents received is 721 students. Data is also gathered for students who had completed their four years of studies at the Faculty and who will attend their Graduation ceremony in October 2012. From the total of 359 graduating students, only 99 had sat for the test, which simultaneously provides $27.58 \%$ response rate. 


\section{Results}

The results for this study are divided into two sections:

4.1 Monitoring for Students Registered in 2010 Who are Currently at Their Third Year of Studies at the Faculty of Engineering and Built Environment

Table 2. Data of a group of Third-Year students starting from the beginning of the year 2010 to 2012

\begin{tabular}{lcccc}
\hline Study year & $\begin{array}{c}\mathbf{n = 3 0} \\
(\mathbf{2 0 1 0} / \mathbf{2 0 1 0})\end{array}$ & $\begin{array}{c}\mathbf{n = 1 3} \\
\mathbf{( 2 0 1 1 / 2 0 1 2 )}\end{array}$ & $\begin{array}{c}\mathbf{n = 1 7 8} \\
\mathbf{( 2 0 1 2 / 2 0 1 3 )}\end{array}$ & \%Increment \\
\hline Self awareness & Year $\mathbf{1}$ & Year 2 & Year 3 & \\
Self regulation & 67.07 & 65.26 & 66.86 & 2.39 \\
Self-motivation & 72.61 & 71.99 & 79.40 & 9.33 \\
Empathy & 80.90 & 80.33 & 81.25 & 1.13 \\
Social skills & 80.38 & 78.20 & 83.10 & 5.89 \\
Spirituality & 78.42 & 76.84 & 81.69 & 5.93 \\
Maturity & 81.64 & 81.21 & 85.44 & 2.95 \\
\hline
\end{tabular}

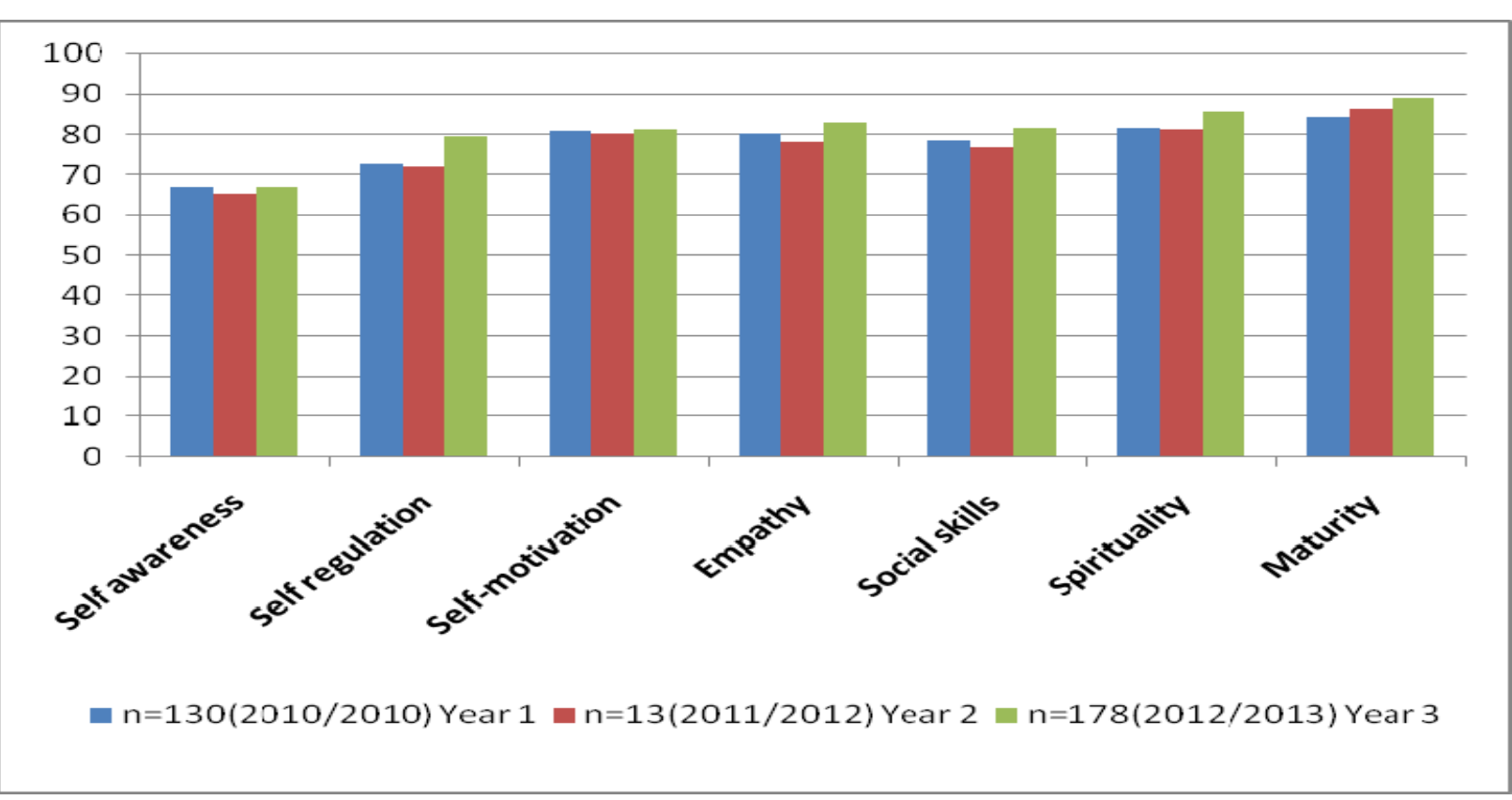

Figure 1. Data of a group of Third Year students starting from the beginning of the year 2010 to 2012

Based on the information in Table 2 and figure1 above, data show a group of Third Year students from the time when they first started in 2010 until 2012 who had sat for the emotional intelligence test. It is found that the percentage of increase of every domain suggests that there is an overall increase. The domain percentage that marks the highest increase is $9.33 \%$ for self regulation domain whereas the lowest domain percentage is noted to be $1.13 \%$ for the self-motivation domain. For the session 2012/2013 for the Third year students who have taken the test, it is found that all domains have had an increase in the percentage from the previous years. 
4.2 The Comparison of Results of First Year Students with Students Who Have Completed Their Studies at the Faculty of Engineering and Built Environment

Table 3. Data of the First Year students right to the students who have completed their final year at the Faculty of Engineering and Built Environment in the session of (2012/2013)

\begin{tabular}{|c|c|c|c|c|c|}
\hline$\underbrace{\text { Population \&Sample }}_{\text {Domain }}$ & $\begin{array}{l}p=237, \\
n=114 \\
(\text { Year 1) }\end{array}$ & $\begin{array}{r}\mathbf{p}=\mathbf{2 2 9} \\
\mathrm{n}=\mathbf{2 0 2} \\
(\text { Year 2) }\end{array}$ & $\begin{array}{r}\mathrm{p}=216 \\
\mathrm{n}=178 \\
(\text { Year 3) }\end{array}$ & $\begin{array}{r}\mathrm{p}=\mathbf{2 6 2} \\
\mathrm{n}=\mathbf{2 3 7} \\
(\text { Year 4) }\end{array}$ & $\begin{array}{c}p=279, \\
n=95 \\
\text { (End of } \\
\text { Study) }\end{array}$ \\
\hline SELF AWARENESS & 67.06 & 65.98 & 66.86 & 69.55 & 67.09 \\
\hline SELF REGULATION & 71.25 & 71.60 & 79.40 & 75.59 & 73.67 \\
\hline SELF MOTIVATION & 78.91 & 78.04 & 81.25 & 81.34 & 77.42 \\
\hline ЕМРАTHY & 79.92 & 80.21 & 83.10 & 83.82 & 81.49 \\
\hline SOCIAL SKILLS & 76.59 & 76.89 & 81.69 & 81.10 & 78.67 \\
\hline SPIRITUALITY & 81.35 & 80.70 & 85.44 & 84.00 & 81.50 \\
\hline MATURITY & 86.55 & 84.97 & 88.90 & 88.31 & 86.28 \\
\hline Total Index & 77.38 & 76.91 & 80.95 & 80.53 & 78.02 \\
\hline
\end{tabular}

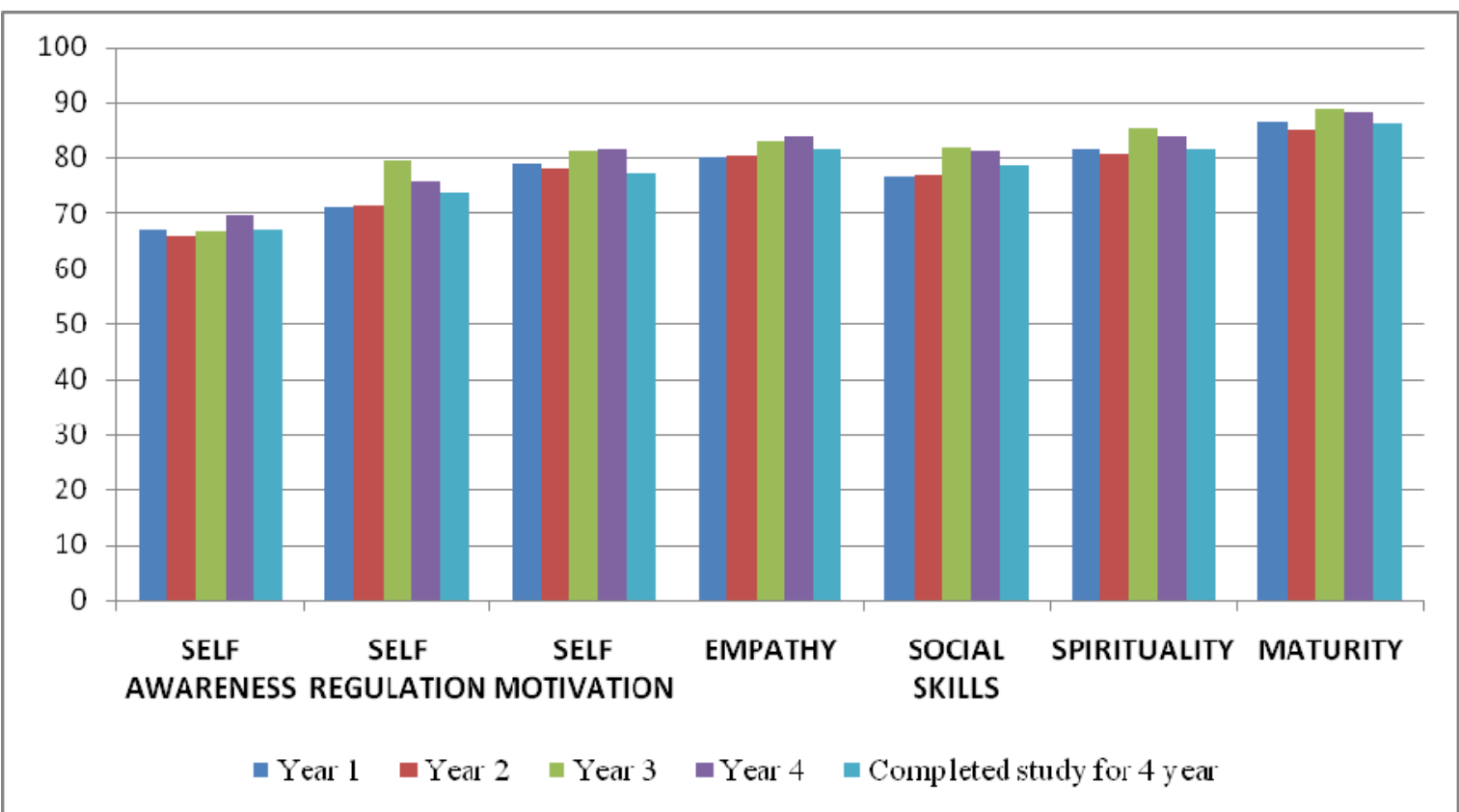

Figure 2. Data of the First Year students right to the students who have completed their final year at the Faculty of Engineering and Built Environment in the session of (2012/2013)

Based on Table 3 and figure 2 above, the data highlight the First Year students as compared to the students who have finished their fourth academic year in the (2012/2013) session. Based on this information, the comparison of results for every domain for the novice undergraduates with the final year students has been conducted. It is found that the overall index average demonstrates the domination of Third-Year students through their highest score of 80.95 while the Second Year students show the lowest overall index average, 76.91. 
Based on Table 2, the maturity domain points to the highest reading with all academic years carry scores that fall within the range of 84.97-88.90 and the domain of self-awareness that notes the lowest range of 65.98-69.55. For the self-awareness domain, there are several sub-domains involved that influence the overall index average score value, among which are emotional awareness, self-evaluation, self-confidence and self-honesty. By revisiting the sub-domains involved, we get to identify with the issues and factors that contribute to the overall index average scores noted, especially for domains that note the lowest score namely the domain of self-awareness.

\section{Discussion}

\subsection{Discussion on the Monitoring of the Students Registering for the Year 2010 Currently in Their Third Year at the Faculty of Engineering and Built Environment}

The results from the analysis demonstrate that the data gathered have pointed out the imbalance in the number of students sitting for the test, whereby there is a remarkable difference in the years (2011/2012) if compared with the years before and after, where at the time the students had registered their courses for the second year. In the First Year (2010/2010), the number of students sitting for the test is 130 people, whereas in the second year (2011/2012) the number of students sitting for the test is 13 students and in the third year (2012/2013) there are 175 students.

It is safe to conclude that for the data gathering in the future, the announcement on this MEQI test should be well spread to get a good number of respondents. However, early hypothesis done assuming that the scores for all domains will be reduced, has fallen short of expectation when the scores for all domains show increment, especially with regards to self-regulation domain and self maturity domain. It draws us to a very interesting discovery to be examined and a more detailed study needs to be done, to know why this phenomenon would happen. Early connection that can be made on the positive changes in the Third Year students' EQ can be concluded by the syllabus structure in Year 1 and 2 involving various methods of delivery and assessment. Among them is the Integration Project in the second year that combines several compulsory subjects whereby the marks from the project contribute to most of the final grade percentage for several Engineering subjects that they have undertaken.

Normally, this Integration Project entails group projects, consisting of various races and both gender decided by the lecturer. Every group will be given the same title, whereby there are several guidelines given. To exemplify this, for the Second year student for session (2011/2012) at the Department of Mechanical and Material Engineering, in the $1^{\text {st }}$ semester, several subjects have been integrated namely Thermodynamics, Engineering Materials and Measurement and Instrumentation to implement the water heating system project. Cooperation and tolerance are required, in realizing the project and there is a presentation session that is to be evaluated. Students spend a lot of time working in groups especially to improve and complete the project. This will help to enhance students' communication skills, time management and their confidence to produce good quality results and also to contribute to students' own EQ development.

In the meantime, in the First Year, the students are exposed to various laboratory works that needs to be completed and here, psychomotor skills and knowledge practicality are important in completing the laboratory assignments given to them. Apart from that, there are several compulsory subjects that prioritise more on professionalism in engineering, like the subject Introduction to Engineering, where it can provide the exposure and better understanding of the Engineering field and also it gives recommendation on the responsibilities that need to be implemented when being in the field, with consideration given on ethical and moral values. During these two years, a number of students are given the opportunity to engaged themselves in several competitions at national level such as the Perodua Eco Challenge, Shell Eco Marathon, and also other competitions that involve other universities. Apart from that, there are various programs that involve engineering students organized by the Engineering Club under the supervision of Engineering Faculty lecturers where it seen to give various positive impacts in the inculcation of unity, cooperation, leadership, self-confidence and other positive values.

All these methods are formed in order to achieve a number of course outcomes and specific programs learning outcomes involving questions and activities to achieve different levels of Bloom's taxonomy. Therefore, we believe these elements contribute to the increased EQ of the students as a whole, where they become more confident individuals, with better personality and become wiser in controlling their emotions. These qualities might drive the students to be more motivated to start their new academic semester and keen to progress to the Third year of their studies. 


\subsection{Discussion on the Comparison of the First Year Students' Results Right to the Results of Students who have Completed Studies at the Faculty of Engineering and Built Environment}

Based on the results obtained, the total number of percentage of students who have taken the test this year, for session $(2012 / 2013)$ for all study years has exceeded 34\% and the highest percentage has been noted for the group who has sat for the test, which is $90.5 \%$ or namely the Fourth Year students. The increased number of respondents can contribute to the accuracy of the data. It is found that the highest score domain is the maturity domain and the lowest is the self-awareness domain.

Being an Engineering student is not an easy thing to embark on, as students are compelled to be more independent and work harder for better results. The students are also exposed to various presentation sessions, individual and group projects, experiments and question-and-answer sessions, making them more mature in managing their learning and co-curriculum activities. At the same time, there has been a concern on self-awareness when students are beginning to feel burdened with the workload of assignments and academic projects assigned to them, and also with the involvement in non-academic activities like cultural performance and sports. Self-awareness serves as an equally significant domain, with others and they need to be balanced.

As the test is being carried out, students have to answer every section of the test or fragments following the domains in a given period of time. Those who have succeeded in answering all the questions will have their scores displayed, based on the range of marks obtained, which suggests the position of the students' EQ levels. The test is a series of questions on different sub-domains and students have to complete all of them. The score results would probably be slightly affected when the students lose focus of the questions, as there are too many questions to answer.

\section{Conclusion}

The MEQI test is able to determine the EQ level of the engineering students, which is also beneficial towards consolidating any domain that is deemed flawed. Effective models can be designed through the integration of certain skills into every assessment method for every course done at the faculty. The skills involved include conflict management, interpersonal, communication empowerment and public speaking. All in all, based on this study, the need to implement some follow-up studies need to be conducted and detailed, in identifying the factors behind every flaw in the results produced, if compared to the hypothesis which suggests that every domain involved will experience a reduction, but the outcome highlights that there are domains demonstrates a high score, as shown by the domain of maturity and the domain with the lowest score, namely the self-awareness domain. A proactive, effective effort needs to be enhanced in aiding weak domains and to obtain clear, elaborated information. This effort should be designed and developed carefully, bearing in mind that it can serve as an added value to help nurture students with high sense of leadership and management skills when they enter the highly competitive career market.

\section{Acknowledgements}

Our greatest appreciation to the National University of Malaysia which has funded this project, under the research grants coded PTS-2011-014 and OUP-2012-126.

\section{References}

Bar-On, R. (1997). The Emotional Quotient Inventory (EQ-i): Technical Manual. Toronto: Multi-Health Systems, Inc.

Boyatzis, R. E., \& Sala, F. (2004). The Emotional Competence Inventory (ECI). See Geher 2004, pp. 147-180.

Goleman, D. (1995). Emotional Intelligence. New York: Bantam.

Janovics, J., \& Christiansen, N. D. (2002). Emotional intelligence in the workplace. Paper presented at the 16th Annual Conference of the Society of Industrial and Organizational Psychology, San Diego, CA.

Lyubomirsky, S., King, L., \& Diener, E. (2005). The benefits of frequent positive affect: Does happiness lead to success? Psychol. Bull, 131(6), 803-855. http://dx.doi.org/10.1037/0033-2909.131.6.803

Mandler, G. (1975). Mind and Emotion. New York: Wiley.

Noriah M. I., \& Zuria Mahmud. (2003). Kepintaran Emosi di Kalangan Pekerja di Malaysia. Prosiding IRPARMK-8 Kategori EAR. Jilid, 1, 184-187.

Petrides, K. V., \& Furnham, A. (2001). Trait emotional intelligence: Psychometric investigation with reference to established trait taxonomies. Eur. J. Personal, 15, 425-448. http://dx.doi.org/10.1002/per.416

Prakash, S., Peter, M., \& Raj, M. (2007). Importance of emotional intelligence in conceptualizing collegial 
leadership in education. South African Journal of Education, 27(3), 541-563.

Salovey, P., \& Mayer, J. D. (1990). Emotional intelligence. Imagination, Cognition, and Personality, 9, 185-211. http://dx.doi.org/10.2190/DUGG-P24E-52WK-6CDG

Schmidt-Atzert, L., \& Buhner, M. (2002). Development of a performance measure of Emotional Intelligence. Paper presented at the 43rd congress of the German Psychological Society, Humboldt-University, Berlin, Germany.

Tett, R. P., Fox, K. E., \& Wang, A. (2005). Development and validation of a self-report measure of emotional intelligence as a multidimensional trait domain. Personal. Soc. Psychol. Bull, 31, 859-888.

Van Der zee, K., Thijs, M., \& Schakel, L. (2002). The relationship of emotional intelligence with academic intelligence and the big five. European Journal of Personality, 16, 103-125. http://dx.doi.org/10.1002/per.434 